\title{
Alear, aleación, ley y otros términos conexos en la Romania medieval
}

\author{
JULIO TORRES
}

Museo Casa de la Moneda

El estudio histórico del léxico tiene como principales puntos de apoyo, en el plano formal, la recogida de variantes diacrónicas, y en el del contenido, la constatación de los sucesivos sentidos y, en su caso, variaciones de significado, de una unidad determinada. Las obras lexicográficas de conjunto, por este mismo motivo, no pueden profundizar a veces lo suficiente en el estudio de algunas o muchas de sus voces. Por lo que se refiere al $D C E C H^{1}$, hasta ahora la única obra completa a la que podemos recurrir los historiadores del léxico castellano, suele fechar la aparición de las formas, pero sin prestar atención a la cronología de las evoluciones y variaciones semánticas, incluso en casos de marcada polisemia. La profundización ha de llevarse a cabo en trabajos específicos, que permitan centrar una pequeña área de trabajo, y aplicar a las palabras o términos estudiados las técnicas de análisis más adecuadas. En este artículo ${ }^{2}$ se pretende explorar el entorno semántico del verbo alear y los sustantivos ley, liga, aleación y otros, dentro del ámbito cronológico de la Edad Media, indagando su procedencia formal y preguntándose acerca de su sentido o sentidos.

El $D R A E^{3}$, s.v. alear $^{2}$, propone como etimología de esta voz el verbo latino alligare, con un significado 'atar', que habría entrado en el idioma a través del antiguo francés aleier. La definición es "producir una aleación, fundiendo

\footnotetext{
' Joan Corominas y José A. Pascual, Diccionario Crítico Etimológico Castellano e Hispánico, Madrid 1980-1991.

2 Este trabajo es una reelaboración del epígrafe 4.3.2.3. de mi tesis doctoral, Ordenanzas medie. vales sobre fabricación de moneda en Castilla. Edición y análisis del vocabulario técnico, leída en el Departamento de Filología Románica de la Universidad Complutense de Madrid en 1998; lo cito en adelante como TORRES, Ordenanzas, y cuando hable, genéricamente, de ordenanzas, me referiré a las estudiadas en ese trabajo.

${ }^{3}$ Real ACademia EsPañola, Diccionario de la Lengua Española, 21 a edición, Madrid, 1992.
} 
sus componentes". Para aleación, el diccionario académico propone dos definiciones, una como nombre de acción, "acción y efecto de alear", y una segunda como objeto, más concretamente como un tipo de material o materia prima: "producto homogéneo, de propiedades metálicas, compuesto de dos o más elementos, uno de los cuales, al menos, debe ser un metal".

El DCECH, s.v. alear $I I I$, propone una definición más sencilla, y, a mi modo de ver, suficiente, aunque excluye la posibilidad de que uno de los componentes no sea un metal: "mezclar dos o más metales fundiéndolos". Coincide con el $D R A E$ en algo que, desde luego, es fundamental, el rasgo ${ }^{4}<$ por fundición $>$ que ha de tener la mezcla o composición. También coinciden ambos en la procedencia francesa y latina del término, si bien $D C E C H$ matiza que el latín alligare es un derivado de ligare. Da como primera documentación (de alear) el año 1713, sin especificar la obra; sin embargo, en la edición Breve de este mismo diccionario ${ }^{5}$, COROMINAS apunta, tanto para alear como para aleación una primera documentación en 1604, que debe corresponder, de acuerdo con su propio listado cronológico, al Diccionario de la Lengua Española y Francesa de Joan Palet. El término ley, con el sentido que aquí veremos, lo documenta, sin embargo, en el siglo XVI. Pero voy a copiar textualmente parte del artículo, puesto que en este trabajo me mostraré contrario a algunos de sus argumentos:

"No es derivado [alear] de ley, como suele decirse. Por el contrario, éste en la ac. 'Calidad de los metales, una vez hecha una aleación'... es adaptación del francés aloi íd (s. XIII; l'aloi entendido como si fuese la loi), derivado del fr. ant. aleiier (también aloiier)... Una forma castiza española se conserva en liga 'ley de los metales' (1601: Herrera)".

Resalta en nota "que en lo antiguo se halla siempre baja ley, ley subida, la ley que..., con un determinativo; el empleo absoluto oro de ley, parece ser reciente". Los comentarios a todas estas afirmaciones, formulados con todo el respeto que merece una de nuestras mejores obras lexicográficas, se irán encontrando, razonados, en las líneas que siguen.

Lo primero que hay que decir es que, tanto de alear como de aleación he podido encontrar, aunque pocas, ocurrencias medievales. El participio de alear aparece en un documento del primer tercio del siglo XIV:

1334, Murcia, $\$ 4^{6}$ : "el maestro que dé a los obreros del argent linpio en fin, $\tau$ que reçiba dellos el contrapeso linpio $\tau$ en fin, $\tau$ que lo dé por

\footnotetext{
${ }^{4}$ No entraré aquí en la discusión acerca de rasgos semánticos y propiedades extralingüísticas, pero creo que esta postura implica ya la convicción de que, al menos en la práctica del análisis, todo rasgo observable en la realidad que, expresado por medio de palabras, sirve para acotar el contenido semántico del término que designa a dicha realidad, es, o puede convertirse en, un rasgo semántico.

"Joan Corominas, Breve Diccionario Etimológico de la Lengua Castellana, Madrid 1980 (3 ed., $2^{\mathrm{a}}$ reimpr.).

"Archivo Municipal de Murcia (AMM), Cartulario 1352-82 Eras, fol. 112-113 (lo cito en adelante como 1334, Murcia). Editado en Juan TORRES FonTES, "La ceca murciana en el reinado de
} 
auentaja a cada çient marcos de obra alea da onça $\tau$ media de obra aleada".

Este documento sigue casi al pie de la letra uno anterior, dado a Lorca en $1297^{7}$, en el que se leía (\$4) "obra oleada", lo que no tiene ningún sentido, y yo lo corregí en mi edición por "obra obrada" basándome en la comparación con un documento parcialmente idéntico, escrito en catalán y promulgado el año anterior $(1296)^{8}$. Aunque aislada, considero que la aparición de 1334 , tanto si es correcta como si es fruto de un error del copista contemporáneo, demuestra la existencia del término, adelantándose con ello la primera documentación en nuestra lengua en casi cuatro siglos con respecto a la datación de $D C E C H$. Otra cosa es el significado, imposible de acotar con los pocos datos que se pueden extraer de este contexto.

Dos siglos más tarde, volvemos a encontrar el verbo alear en un contexto castellano, en un documento emitido por Juan II de Castilla en 1442": "las buenas doblas valadíes que en mis regnos e sennoríos se usaban e tractaban, se labraban e habían labrado en la casa de la moneda de Málaga e en otras partes, e eran aleadas a la ley de diez e nueve quilates de oro fino". En este texto parece que alear es 'poner un metal a determinada ley', sentido que quizá sea previo a su extensión como 'mezclar metales fundiéndolos', y no a la inversa. En la realidad no existe ninguna diferencia entre mezclar metales por fusión y poner uno de ellos a la ley. La operación es la misma, pues la mezcla ha de efectuarse obligatoriamente bajo unas determinadas condiciones y en dosis precisas. Sí parece existir una leve diferencia de concepto, o psicológica, que se traduce en el discurso en el empleo de una u otra redacción.

Alfonso XI", en Mélanges offerts à Jean Gautier Dalché, Nice 1983, págs. 295-313, doc. II, págs. 310-312. Edición crítica en TORRES, Ordenanzas, págs. 58-64; a esta edición se refieren los números de párrafo que indico precedidos del símbolo §. Encabezo las citas de documentación por el año y lugar de emisión, seguido, en su caso, del número del párrafo de mi edición.

${ }^{7}$ Citado como 1297, Lorca: Ordenamiento de Fernando IV para acuñar moneda en Lorca, Archivo Municipal de Lorca, pergaminos de Fernando IV, núm. 17. Ediciones: Rafael Espín RaEl, Privilegio para labrar moneda en Lorca, dado en Toro, por el rey Fernando $N$, en 24 de octubre de la era de 1335 , Lorca 1936; JUAN TORRES FonTES, Repartimiento de Lorca, Murcia 1977, doc. XXV, pág. 95 ss.; y JUAN TORREs FonTES, Documentos de Fernando IV, Colección de documentos para la Historia del Reino de Murcia V, Murcia 1980, doc. XXII, pág. 26 ss. Edición crítica en TORRES, Ordenanzas, págs. 48-57.

${ }^{8}$ Citado como 1296, Alicante: Ordenamiento de Jaime II para labrar moneda murciana en Alicante, Archivo de la Corona de Aragón (ACA), reg. 105, fol. 206. Ediciones: Joaquim BOTET I SISÓ, Les monedes catalanes (en adelante BOTET, Monedes), Barcelona 1908-1911, vol. III, doc. XVI, pág. 280 , con el título "Orde del rey don Jaume II pera que s'encunyés a Alacant moneda de plata y de billó, ab curs en tot lo Regne de Murcia y instruccions sobre la llur encunyació"; JUAN TORRES FONTES, Documentos del siglo XIII, Colección de documentos para la Historia del Reino de Murcia II, Murcia 1969, doc. CXXII, pág. 124; y JuAn Manuel Del Estal, El Reino de Murcia bajo Aragón (1296-1305). Corpus documental 1/2, Alicante 1990, doc. 79, pág. 79.

${ }^{9}$ Ordenamiento para labrar moneda en las casas della. Ediciones: Aloïs HeIss, Descripción general de las monedas hispano-cristianas desde la invasión de los árabes (HeIss, Descripción), Madrid 1865, tomo I, pág. 301, doc. XVIII; y Liciniano SÁEZ, Apéndice a la crónica nuevamente impresa del señor rey don Juan el II. En que se da noticia de todas las monedas, de sus valores, y del precio que tuvieron varios géneros en su reinado (SÁEZ, Juan II), Madrid 1786, pág. 97, doc. VII. 
Ya al final de la Edad Media, o principios de la Moderna, encontramos el nombre aleación, sin contexto explicativo, salvo que es una operación realizada por el ensayador, al menos en algunas ocasiones:

1497. Medina del Campo ${ }^{10}$, §47: "ha de ser a su cargo [del ensayador] poner hornillos $\tau$ copelas $\tau$ plomo $\tau$ caruón para el ensay, $\tau$ aguas fuertes $\tau$ redomas $\tau$ plata $\tau$ las otras herramientas que pertenescen a su officio, $\tau$ fazer las aleaciones a los mercaderes que vinieren".

Con estas tres únicas ocurrencias en castellano poco fruto podríamos obtener si no recurrimos a otros textos románicos, no ya por aumentar la cantidad de contextos, sino en busca de datos significativos más explícitos. La cronología de las citas nos permitirá aventurar o no paralelismos y transferencias entre unas lenguas o áreas lingüísticas y otras.

Dentro de la Romania, la primera ocurrencia que he encontrado del verbo alear procede de Barcelona y se encuentra en un documento de 1257 escrito en latín: "de una marcha monete aleyada exeant decem et octo solidos denariorum" "L . La siguiente ocurrencia, ya con el verbo conjugado, es en Francia, en 1275: "Et les monnoies qui ont esté allegiés sanz faire diffeu rance apperte, nous voulons quelles chéent et que elles soient abatues... Nous commandons que nul baron n'alegent la monnoie que il auront commencié de pois ou de loi, sanz faire diffeu rance apperte devers croiz ou devers pile qui puis estre conneue de toutes genz"12. En este contexto la interpretación es más bien "rebajar la ley' o, incluso, el peso. Este extracto nos introduce además en el problema de la supuesta confusión producida en francés entre l'alloi y la loi que, como vemos, ya se habría producido en esta época, pues hay una ocurrencia de loi. En el ámbito catalán, para el que dispongo de documentación más antigua, se atestigua lege (latín) desde la segunda mitad del siglo XII y en el ámbito francés a principios del XIII ${ }^{13}$, y, hacia mediados de ese siglo (1261, Coimbra), aparece en el ámbito portugués: "debeo augere eam secundum eandem legem et eandem quantitatem cupri et argenti secundum quam predictam noua mea a principio fuit facta"14. En 1272, encontramos, en el ámbito francés, el siguiente contexto, donde el término aparece en nominativo, y resulta ser lex $x^{15}$ : "Lex

${ }^{10}$ Quaderno de Ordenanças de la lauor de la moneda. 1497 junio 13. La primera edición conocida es en Libro en que están copiladas algunas bullas de nuestro muy sancto Padre concedidas en fauor de la jurisdicción real de sus altezas * todas las pragmáticas que están fechas para la buena gouernación del reyno..., [Alcalá de Henares 1503] (citado en adelante como Bullas y Pragmáticas), fol. CXCVII b ss. Edición crítica en TORRES, Ordenanzas, págs. 154-193.

"ACA, reg. 24, fol. 69-70 de Jaime I. En BotET, Monedes, III, doc. IV, pág. 244.

12 Philippe III; L'ordinations de la monoie. En F. DE SAULCY, Recueil de Documents relatifs à l'Histoire des monnaies frappées par les rois de France depuis Philippe Il jusqu'à François l (4 vols., en adelante SAulcy, Recueil), París-Caen-Mâcon 1879-1892, vol. I, pág. 142.

${ }_{13}$ Ver las citas textuales más adelante, al hablar de ley.

14 Portvgaliae Monvmenta Historica (Academia de Ciencias de Lisboa, 1856-1888), Leges, I, pág. 210 y ss.; Reinado de Affonso III, doc. IX.

${ }_{15}$ Subrayo esta obviedad porque se podría pensar que al cambiar de sentido se hubiera perdido la conciencia de la relación inicial con lex. Al no ser así, la secuencia comúnmente aceptada ligare $>$ alligare > aleier / aloier >l'aloi > la loi se convierte, como vamos a ver, en lex > allegare... 
vero dictae mone tae talis est et talis esse debet, quatuor denariorum minus pita ad argentum Monspesulani" 16 . Las variantes aloy y alloy son mucho menos frecuentes; he encontrado sólo tres contextos, y los tres en francés. Quizá haya que poner en duda, por tanto, que ley provenga de la confusión que según $D C E C H$ y otros autores habría tenido lugar en el ámbito del francés y se habría extendido luego a otros territorios, y proponer que lex, experimentó una especialización semántica en el campo conceptual relacionado con los metales preciosos, con un sentido de 'composición justa'. Aleier y aloier serían, pues, derivados de lege, y no al contrario. En este esquema encuadraría perfectamente el sentido inicial del verbo como 'poner a la ley' que se va confundiendo paulatinamente con el simple hecho de 'mezclar metales fundiéndolos', como habíamos empezado a ver y seguiremos viendo a continuación.

El participio del verbo alleyar se repite insistentemente en un documento, también catalán y ya en esta lengua, de 1331: "argent alleyat per fer diners menuts... que liuràs a fondre d'argent alleyat per fer diners d'argent, XLIIII millia D marchs XIX diners IIII grans e mig d'argent fi... XLVI millia DCXXII marchs VII unces VII ternals d'argent alleyat qui foren liurats a fondre per fer moneda d'argent... CCCCLXXIX marchs VII unces II ternals d'argent alleyat" ${ }^{\prime \prime}$. El manual de mercadería de la segunda mitad del siglo XIV publicado por Miguel GuAL es más contundente aun: "Si volç saber de les monedas d'aur e d'argent com són aleyades, ço és a dir de qual ley són"18. Otro de 1362, dado en Perpignan por Pedro IV, parece que incide en el significado de 'poner a la ley': "alleyant la dobla a XXIII quirats e quart, els reyals de Mallorques a XXIII quirats e mig, els ryells empero o vergues per ço com se fan de moltes e diverses monedes e tenen diverses leys sien alleyats a la ley que per los guardes o veedors per lo dit senyor rey a açò diputats seran jutjades"19.

Por un documento algo anterior a este último (1347), sabemos que en Francia, a mediados del siglo XIV, el encargado de efectuar las aleaciones era el maestro de moneda: "Le roy... a ordonné en son conseil que l'on fera deniers d'or à l'escu de 23 karats, c'est à scavoir le $24^{e}$ karat moitié argent fin et moitié cuivre fin, de 54 de poids au marc de París, pour lesquels faire nous vous envoyons le patron tant du denier comme de la loy, et un lingot, et en oultre un desdits deniers monnoyés, et dix mars d'argent fin, et dix marcs de cuivre fin, pour faire vostre alloy; et voulons que Bernard Coursin soit maistre de l'or de ladite monnoye, et luy commander, de par le roy, qu'il alloie tout l'or qui vous viendra, de l'argent et du cuivre fin que nous vous envoyons, à plus près dudit patron; et vous envoyons le fort, droit et le foible..." ${ }^{20}$. Los términos loy y alloy

${ }^{16}$ Saulcy, Recueil, I, pág. 141.

${ }^{17}$ Documento de 1331 incluido en otro de 1338. ACA, Reg. 1298, fol. 95 y ss. En Botet, Monedes, III, doc. XXII, pág. 292 y ss.

${ }_{18}$ Miguel Gual Camarena, El primer manual hispánico de mercadería (siglo XIV), Barcelona 1981 , pág. 111.

${ }_{19}$ ACA, reg. 1293, fol. 98. En BotET, Monedes, III, doc. XXXIV, pág. 330.

${ }^{20}$ Ordonnance des généraux des Monnoyes aux gardes et maistres de la Monnoye de Toulouse... En SAulcy, Recueil, I, pág. 258. 
pueden interpretarse aquí como 'mezcla', aunque el segundo también podría ser la mezcla sólo de cobre y plata añadida al oro, es decir, lo que hoy llamaríamos la liga. En Barcelona, en 1388, era obligatoria la presencia de las guardas durante el proceso de la aleación, realizada también por el maestro: "que les guardes de les dites seques sien presents com los maestres alleyaran"21. Como equivalente de alear se debe registrar también el verbo ligar de un documento veneciano de 1381: "per ser Crisstofalo Zanchani, masser in la Moneda da l'arçento, fose ligado marche 39 de arçento e dado a Checho fonedor a infonder, el qual Checho çonsse intro la dita liga peça una d'arçento de marche 15 , la qual peça era bona de bolla, et oltra quella çonsse çercha marche 4 de arçento, el qual elo avea trovado per fonedura, el qual tuto insembre fo fondudo per lo dito Checho e reduto in verge"22.

El término sigue vacilando entre un sentido y otro, o en ambos. En el mismo documento barcelonés de 1388 citado en el párrafo anterior, encontramos, gracias a una correspondencia sintáctica, el ejemplo más claro de 'poner a la ley': "que les dites guardes, ans que donen licencia de deliurar los dits florins, ab sobirana diligencia regoneguen quels dits florins sien cascun a la talla e a la ley a que deuen esser tallats e alleyats". Donde:

'poner a la talla' = tallar
'poner a la ley' = alleyar

Poco más tarde, en 1417, en Valencia, encontramos una de las más claras ocurrencias con sentido 'mezclar': "Com lo maestre volra ffondre argent e uolra ffer ffondicio, primerament ensemps ab les guardes deu aleyar son argent ab coure e ab billo segons la ley de la moneda que deura ffer. Apres quan sera feta la liga deu metre per cresol o per caça ço que li plaura. E com l'argent passara a la liga deuen hi esser les guardes" 23 . Se habla ya de alear unos metales con otros, y parece que se está perdiendo la consciencia de una conexión entre alear y ley. El hecho de que la operación de alear y el producto de ésta reciban el nombre de liga, y no ley, incide en el orden de aparición propuesto:

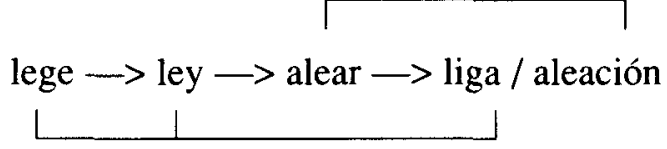

En castellano, $D C E C H$ tiene registrado liga con este sentido en Nebrija (1495), pero yo sólo he encontrado una ocurrencia de ligadura, en 1478, y en

${ }^{21}$ ACA, reg. 1975, fols. 1 y 2. En Botet, Monedes, III, doc. XL, pág. 352.

22 Il "Capitolar dalle broche" della zecca di Venezia (1358-1556) (en adelante Venezia 13581556), a cura di Giorgetta Bonfiglio Dosio, Padova 1984, pág. 42.

${ }_{23}$ Archivo General del Reino de Valencia (AGRV), Títulos y enajenaciones (tít. y enaj.), vol. II, fols. 228-230. En Felipe MATEU y LLOPIS, "El vocabulari medieval de l'exercici de la monederia segons documents valencians" (en adelante MATEu, "Vocabulari"), en Butlleti de Dialectologia Catalana 24, 1936, pp. 98-126, doc. I, pág. 112. 
un texto culto: "porquel oro que en Francia y en Aragón se labra es de peso de quatro tomines de oro e dos de ligadura"24.

También he encontrado alear y alliar en el ámbito portugués, en un documento de 1460: "...nem os possam vender nem dar, nem trocar, nem escambar, nem alear nem lavrar, nem alliar com prata..."25.

En un principio, como veremos a continuación, la sucesión que acabo de proponer se realizaría léxicamente como sigue:

\begin{tabular}{c|c|c|c} 
'grado de pureza' & $\begin{array}{c}\text { 'operación para obtener } \\
\text { un grado de pureza' }\end{array}$ & 'mezclar metales' & $\begin{array}{c}\text { 'resultado de la } \\
\text { operación' }\end{array}$ \\
\hline ley & alear & alear & ley
\end{tabular}

Esta distribución no implica conflicto en cuanto a los dos sentidos centrales, ya que como sabemos son simples variantes estilísticas que responden a diferencias de enfoque psicológico. El conflicto se plantea en los extremos, y se ha resuelto en castellano moderno con la creación del posverbal aleación. En la época medieval que analizamos, solamente el francés, y muy tímidamente, ha dado este paso, mediante la creación de aloi que, paradójicamente, en francés moderno ocupa también la primera casilla, desterrando al significante loi del ámbito lingüístico de la metalurgia. Posteriormente se crearía alliage, partiendo de allier, para ocupar la casilla cuarta.

A continuación voy a repasar, siguiendo cronológicamente los textos, los intentos de resolver este conflicto. Nos fijaremos para ello en los términos ley y liga (que en un primer momento parecen sólo variantes de pronunciación o de escritura), y, posteriormente, veremos un tercer término, ventaja, que también podría estar emparentado semánticamente en uno de sus sentidos con la operación de alear.

Ley aparece en castellano desde las primeras ordenanzas sobre fabricación de moneda (1297, Lorca / 1334, Murcia, $\$ 1$ de ambos), en contextos difíciles de interpretar: "dos dineros de ley enblanquida argente fin" y "tres dineros de ley argente fin enblanquidos", respectivamente. A pesar de su extraña redacción, la cita introduce uno de los contextos habituales en que aparece el término en otras ordenanzas, como una magnitud cuya unidad de medida para la plata es, en principio, el dinero de ley. En 1400 , Cuenca ${ }^{26}, \S 1$, se menciona por

${ }^{24}$ Epístolas de mosén Diego de Valera enbiadas en diversos tiempos e a diversas personas, Madrid, 1878., XXIII, pág. 83.

${ }^{25}$ Livro das vereações da Camara do Porto do anno 1460, fol. 65v. En Carlos Augusto TeiXeira DE ARAGÃo, Descrição geral e histórica das moedas de Portugal (3 vols.), Lisboa 1874-1880, tomo I, doc. 33, pág. 382 .

${ }^{26}$ Archivo General de Simancas (AGS), Diversos de Castilla (DC) 4, 57. Editado parcialmente en Juan BAUTISTA BARTHE, Colección de documentos para la historia monetaria de España, Madrid 1843, págs. 19-21, y en HeIss, Descripción, tomo I, doc. IX, p. 291. Edición completa en Julio TORRES, "El Ordenamiento de Cuenca", Nvmisma 238, Madrid 1996, págs. 123-146 (transcripción en págs. 132-139), y edición crítica en ToRREs, Ordenanzas, págs. 69-75. 
primera vez el submúltiplo del dinero, el grano, pero la relación cuantitativa entre ambos no puede ser deducida de los textos. Las unidades de ley para el oro se introducen en 1461, Aranda ${ }^{27}, \S 43$, con la misma escasez de información cuantitativa.

En los párrafos 7 de las ordenanzas de 1297 y 1334 se alude a "mezcla ninguna de otra ley" 28 , pero el contexto más parece referirse a mezcla en sólido de metales de diferente ley, y no a lo que hoy llamamos aleación.

Un ordenamiento sevillano de $1369^{29}$, en sus párrafos 1,4 y 5 , es el único que informa mínimamente sobre cómo efectuar la aleación o puesta a la ley, en los siguientes párrafos:

$\S 1:$ :a ley de tres dineros de plata de onze dineros, que es a saber, a la dicha ley vn marco de plata $\tau$ tres de cobre".

Se puede deducir: si 3 dineros equivalen a un cuarto de la aleación, el cien por cien, 12 dineros, será el máximo de ley de la plata. Por tanto, la plata que sirve de base en este caso (ley monetaria) tiene un dinero menos que el máximo posible ${ }^{30}$. Se confirma en el siguiente párrafo con la relación 1 dinero y medio $=$ un octavo de la aleación.

$\S 4$ : "vn dinero $\tau$ medio de plata $\tau$ que sea de ley de onze dineros, es a saber, que vn marco de plata de liga de onze dineros han poner siete de cobre".

El último de los párrafos que transcribo del ordenamiento de 1369 se limita a especificar la mezcla que ha de hacerse:

§5: "en cada vn marco de plata de liga de onze dineros quinze de cobre".

pero podemos deducir que la ley de esta moneda será de tres cuartos de dinero por marco (la mitad de un dinero y medio), ya que la plata es sólo un dieciseisavo de la aleación. Obsérvese también que estos contextos escriben liga donde se suele escribir ley. Es quizá el ejemplo más claro de este fenómeno que, como tendremos oportunidad de ver, es habitual, y nos permitirá proponer que ley y liga, aun siendo más frecuente el primero, aparecen en contextos semejantes durante el período estudiado y en todos los ámbitos linguísticos contemplados.

27 AMM, Cartulario real 1453-1478, fols. 120r-124v. Ediciones: María C. Molina Grande, Documentos de Enrique IV, Colección de documentos para la Historia del Reino de Murcia XVIII, Murcia 1988, doc. 149, págs. 349-365. Edición crítica en TORRES, Ordenanzas, págs. 76-99.

${ }^{28}$ También en los párrafos semejantes de las ordenanzas posteriores.

${ }^{29}$ AMM, Cart. Real 1405-18 eras, fols. 16r-17r. Ediciones: Lope Pascual Martinez, Documentos de Enrique II, Colección de documentos para la Historia del Reino de Murcia VIII, Murcia 1983, doc. V, pp. 7-10. Edición crítica en TORRES, Ordenanzas, págs. 64-68.

${ }^{30}$ La ley más habitual de la plata monetaria fue de 11 dineros y 4 granos, a partir de $1461, \$ 39$. 
Si comparamos el contexto

"ley de tres dineros de plata de onze dineros"

con los de 1297 y 1334

"dos dineros de ley enblanquida argente fin"

"tres dineros de ley argente fin enblanquidos"

concluiríamos que

$$
\begin{aligned}
\text { plata de } n \text { dineros } & =\text { enblanquida argente fin } \\
& =\text { argente fin enblanquidos }
\end{aligned}
$$

Esta forma literaria, no cuantitativa, de denominar la ley monetaria cuyo valor se supone conocido, debió ser habitual en la época de estos dos primeros textos, pues encontramos expresiones similares en el ámbito francés desde 1180: "Gros tournois d'argent a $12 \mathrm{~d}$. de loy argent le roy" 31 . Ya en el latín imperial se encuentran métodos no cuantitativos de expresión de la ley, como argentum pusulatum, o aurum obryzum. En el ámbito catalán se emplean diversas expresiones, pero en 1296, Alicante, encontramos: "moneda d'argent que sia a ley de XI diners, comtant argent a XI diners e mala emblanquida", por lo que lo más probable es que estas extrañas expresiones castellanas no sean sino malas traducciones del documento catalán, el cual expresa claramente que la ley monetaria de su plata ha de ser de 11 dineros y medio ${ }^{32}$, mayor que la castellana de 1369. También puede que en 1297, Lorca, se esté dando por supuesto que la ley emblanquida es la de once dineros y medio. En cuanto al significado del adjetivo emblanquida, que aparece también en contextos coincidentes con ocurrencias de fina o pura, podría ser afinada. Gual Camarena ${ }^{33}$ recoge la siguiente cita catalana, también de 1296: "Argent de Montpesler o d'altre bon e fin argent... e que'l dit argent isca blanch del foch" ${ }^{34}$. Esta cita podría explicar el sentido de nuestro emblanquida, que se referiría al color que distingue a la plata en el homo cuando ya está fina, y nada tiene que ver con la posterior blanquición que recibían a veces las piezas. Este mismo autor aporta otra cita, de un arancel de 1284 , en la que se describe la ley del metal de un modo a la vez literario y cuantitativo, aunque en este caso no se refiera a la plata fina, sino ya aleada a ley de cuaterno (quaternus > casern): "tot cambi fondedor, qui sia

${ }^{31}$ Ms. fr. 5524, fol. 33 / Registre de Lotier [de Lautier], fol 36 à 37. En SAulCY, Recueil, I, pág. 116. Saulcy lo da en francés, pero debe ser traducción suya del latín.

${ }_{32}$ Mala (mealla) era el nombre de la moneda (o el valor) de medio dinero y se utilizó también, como vemos aquí para denominar al medio dinero de ley.

${ }^{33}$ Miguel Gual Camarena, Vocabulario del comercio medieval. Colección de aranceles aduaneros de la Corona de Aragón (siglos XIII y XIV) (en adelante GUAL, Vocabulario), Barcelona 1976 (ed. orig. Tarrago na 1968), pág. 205, s.v. anaps.

${ }^{34}$ Ordenanzas de plateros de Perpignan; tomado por Gual de B.-J. ALART, Documents sur la langue catalane des anciens comtés de Rousillon et de Cerdagne, París, 1881, docs. 119 y 120. 
de ley de casern aual, I meala lo march. Item tot cambi qui sia de mes de casern, I diner lo march" 35 .

Debemos dar por sentado que el término ley como medida de pureza, podía pertenecer al patrimonio léxico de toda la Romania, y que no es necesario hablar de préstamo en la época de las primeras documentaciones, que, para el castellano, podemos anticipar aun en algunos años recurriendo al siguiente texto de las Cortes de Jerez de 1268: "La moneda de los dineros alfonsís que yo mandé faser después que comencé la guerra, que la confirmase para en todos mios días, e que la non creçiese nin menguase, nin en la ley nin en la talla que agora es" 36 .

Ya he comentado que, en la documentación catalana consultada, aparecía a finales del siglo XII. Estos son los textos:

1174 Vich: "monetam facio de lege quatuor denariorum argenti puri et de legitimo pondere, ita quod XVIII solidi denariorum exeant ad marcam; et ut ista moneta in predicta lege et pondere firmiter observetur et teneatur... convenio etiam quod prescripta moneta non mutetur in omni vita mea, nec in lege nec in pondere minuatur per meum consilium vel stabilimentum vel voluntatem" ${ }^{37}$.

1162 - 1196 s.l.: "facio et stabilio monetam novam Barchinonensem bonam et legalemque omnibus diebus vite mee per terram meam curret. Quam monetam facio et statuo fieri ad quatuor denarios argenti fini sive puri. Et quod exeat marcha denariorum ad XVIII solidos. Predictam vero monetam volo et facio firmam et stabilem in predicto penso et lege" 38 .

Una vez más nos encontramos con lege en el sentido de medida de pureza. Aunque no le doy más importancia que la de resaltarlo, quiero subrayar que, además, en este texto y en algunos otros, se utiliza el adjetivo legalis, derivado de lege, como sinónimo de 'de ley'. Los adjetivos purus y finus, que aparecen en estos textos calificando a la plata son el modo más habitual de nombrar a la plata monetaria en el ámbito catalán en esta época.

La primera aparición encontrada de lege en ámbito francés es de 1202:

"moneta autem exiet de ferris per XXX sol. ad marcham monetam Flandrie, et tenebit de lege quatuor sellingorum marcha" ${ }^{39}$.

${ }^{35}$ Gual, Vocabulario, doc. XVI, §85, pág. 145. La ley cuaternal, de 4 dineros de plata por marco, parece demasiado elevada para 1284, pero GuAL no expresa ninguna duda acerca de la fechación.

${ }_{36}$ Cortes de los antiguos reinos de León y Castilla (Cortes), Real Academia de la Historia, Madrid, desde 1861, tomo I, pág. 64.

${ }^{37}$ ACA, perg. 160 de Alfons I. En Botet, Monedes, I, doc. XVI, pág. 211. Botet utiliza la nomenclatura catalana en la sucesión de los monarcas, de manera que Alfons I corresponde a Alfonso Il de Aragón.

${ }^{38}$ ACA, reg. 2, fol. 47r de Alfons I. En BotET, Monedes, III, doc. II, pág. 240.

${ }^{39}$ Philippe II Auguste; Carta de moneta tornacensi; Bibl. Nat., Cartulaire de Philippe-Auguste, pág. LXXI V ${ }^{\circ}$ Ord., XI, 285 / Rev'ue Belge, III, 445. En SAULCY, Recueil, I, pág. 117. 
A continuación transcribo, a manera de inventario cronológico, algunas otras ocurrencias de lege y ley encontradas en las diferentes lenguas y ámbitos lingüísticos:

1222 Huesca: "non faciemus nec fieri permittemus vel consenciemus cudi aut fabricari mo netam jaccensis figure vel alterius cuiuslibet valoris nec istam mutabimus et [augebimus] numero aut diminuemus penso et lege" ${ }^{\prime 40}$.

1226: "monetam nostram Turonensem... cudendam et faciendam de pondere et lege quibus debent esse" 41

1247 Valencia: "ad legem trium denariorum, exeunte argentum ad undecim denarios et obo lum"42.

1471 (30-VII) Medina: "E que los cambios estén bastecidos de moneda de ley, e la den e tomen a los precios por mí ordenados, e que no pongan en ellos ni den monedas sin ley" ... "en cada una desas cibdades e villas e logares pongades veedores, omes que sepan conocer la ley de moneda... para que los quartos que fallaren que fueren buenos los tomedes, e los que fueren falsos e no tovieren ley los foraden con clavo e los tornen a su dueño" 43 .

1488 (13-X) Valladolid: "que ninguno sea osado de desechar pieça de oro porque esté quebra da ni soldada, o tenga qualquier falta de granos, tanto que sea de la ley que deue tener" ${ }^{24}$.

He dejado para el final, alterando el orden cronológico, los siguientes textos. El primero, francés, en el que conviven dos sentidos diferentes de loy, término del que no he aportado citas por responder todas ellas al sentido principal esperado:

1349: "ceux qui feront leur loy à ouvrer gros tournois d'argent, à 6 deniers de loy, auront pour chacun marc d'argent, en billon blanc, $7 \#$ tz., et ceux qui feront leur loy à 2 deniers 12 grains de loy auront pour chacun marc d'argent, en billon noir qu'ilz aporteront à la monnoye, $6 \#$ 15 s. tournois" 4 .

${ }^{40}$ ACA, Cartes reyals de don Jaume I, $n^{0}$ 151. En Botet, Monedes, III, doc. V, pág. 247.

${ }^{41}$ Sin indicación de lugar. SAULCY, Recueil, I, pág. 121.

42 AGRV, Libro III de enajenaciones, fol. 97v.; Archivo Municipal de Valencia, Perg. 13. En Felipe MATEu i Llopis, Ensayo sobre una Casa Real de Moneda de uno de los Estados de la Corona de Aragón. La Ceca de Valencia y las acuñaciones valencianas de los siglos XIII al XVIII, Valencia 1929.

${ }^{43}$ HeISS, Descripción, I, 313, XXIV y Liciniano SáeZ, Demostración histórica del verdadero valor de las monedas del reynado de don Enrique $I V$, Madrid 1805, pág. 498, XI.

${ }_{44}$ Declaración sobre la manera que se ha de tener en el pesar de la moneda de oro $\tau$ de otras cosas, en Bullas y Pragmáticas fols. CCXXXIIa - CCXXXIIIb.

${ }^{45}$ Philippe VI; Ordonnance des généraux... En SaulCY, Recueil, I, pág. 271. 
Loy es aquí, a la vez, 'medida de pureza' y 'mezcla'. El segundo es un texto catalán en el que conviven ley y lega, término este último que se introduce para denominar a la parte secundaria de la composición, oponiéndose ya a ley como medida de pureza:

1388 Barcelona: "fabricada una toca a ley de XVIII quirats d'or fi" ... "sien meses egualment ensemps, axí com se pertany, en ciment, tantes vegades tro tota la lega sie d'aquelles fora" ... "E com tota la lega ne sie fora, sien tornades pesar... les dites guardes jutgen e declaren la ley a que hauran trobats los dits florins" 46 .

Este texto nos introduce en el concepto de liga, en el sentido que acabamos de ver, y da pie a la presentación, también cronológica, de las ocurrencias encontradas de liga, y, en algún caso, de ligar. La primera de ellas es de principios del siglo XIV:

1308 Valencia: "L'offici del maestre es aytal: que deu aleyar en presencia del scrivà del rey e de les guardes, puys deu liurar al fonedor aquel argent aleyat, quel fona... E axí lo dit asaiador es en la moneda per provar si el maestre fa justament la $\mathrm{lia}^{\prime \prime 4}$.

Aquí lia es el resultado de la operación de alear. Sin embargo, en el siguiente fragmento, medio siglo después, es, a la vez, un sinónimo de la acepción más generalizada de ley, como medida de pureza (primer extracto), y aquella parte de otro metal que se mezcla al principal $^{48}$ para conseguir una pureza determinada (segundo extracto).

1356 Perpignan: "E ixen de I march d'or de dobles obrat ab la liga de XXIII quirats menys quart LXIX florins, que valen comptant lo a XII sol. II diners per florí, XLI libs. XXIX s. VI ds." ... "met hom en lo march del or fi liga d'argent VI diners per march" ${ }^{\text {. }}$.

En las ordenanzas medievales castellanas que he revisado sólo hay ocurrencias de liga en 1369, Sevilla, en los párrafos 4, 5 y 6, donde aparece como sinónimo de ley, o más bien son empleados ambos términos el uno por el otro con cierta arbitrariedad.

Para simplificar el resto de la exposición cronológica, emplearé las siguientes referencias de sentido, tanto para ley, como para liga y las otras variantes, indicándolo entre paréntesis:

${ }^{46}$ ACA, reg. 1975, fols. 1 y 2. En Botet, Monedes, III, doc. XL, pág. 352.

${ }^{47}$ ACA, Reg. 231, fol. 31 y ss. En Botet, Monedes, III, doc. XVIII, pág. 283.

${ }^{48}$ Utilizaré la nomenclatura metal principal para denominar a la plata o al oro, considerados como base de las aleaciones monetarias, y metal secundario a lo que hoy día llamamos liga. Lo he preferido a metal noble / no noble, u otra similar, porque en la liga del oro interviene la plata, que es metal noble.

${ }^{49}$ ACA, paper solt. En BOTET, Monedes, III, doc. XXXII, pág. 325. 
- $S_{1}$ (sentido 1): medida de pureza, o proporción de metal principal.

- $\mathrm{S}_{2 \mathrm{a}}$ (sentido 2a): la operación de mezcla de los metales.

- $\mathrm{S}_{2 b}$ (sentido $2 \mathrm{~b}$ ): el resultado de la operación anterior.

$-\mathrm{S}_{3}$ (sentido 3): la parte de metal secundario que se mezcla al principal.

En algunos contextos los cuatro sentidos se neutralizan en $S_{1}$, puesto que no son sino diferentes formas de expresar una misma realidad, según el punto de vista que se adopte.

1357 (ámbito francés): "denarii albi curribiles pro decem octo denariis ad octo denarios argenti fini de liga $\left(\mathrm{S}_{1}\right)$ et de pondere IX sol. den. pro marcha... Item denarii nigri currentes pro sex denariis, de liga $\left(\mathrm{S}_{1}\right)$ IIII den. argenti fini, et de pondere XIII sol. IV den. dictae monetae... Item denarii nigri curribiles pro III den., ad II den. et XII gr. de liga $\left(\mathrm{S}_{1}\right)$, et de pond. XVI sol. VIII den. pro qualibet marcha dictorum denariorum... Et possunt esse in fretone duo fortes et duos debiles... Item denarii niggri curribiles pro I den., de liga $\left(\mathrm{S}_{1}\right)$ I den. argenti fini, et de pond. XXII sol. III den. pro qualibet marcha..."

1360 Aquileya: "juste fore inventa tam in liga $\left(\mathrm{S}_{1}\right)$ quam in pondere"51.

1363 Delfinato: "ordinamus et volumus et disponimus de caetero monetas nostras infra Sacrum Romanum Imperium sub modis, ligis $\left(S_{1}\right)$, formis, remediis \& conditionibus infrascriptis, cudi \& fieri ut sequitur in hunc modum" ... "quod fiat una moneta aurea quae appellatur regalis... \& sint ligae $\left(\mathrm{S}_{1}\right)$ XXIV karatorum minus quarta parte unius karate" 52 .

1381 Venecia: "per ser Crisstofalo Zanchani, masser in la Moneda da l'arçento, fose ligado ${ }^{53}$ marche 39 de arçento e dado a Checho fonedor a infonder, el qual Checho çonsse intro la dita liga $\left(\mathrm{S}_{2 \mathrm{~b}}\right)$ peça una d'arçento de marche 15, la qual peça era bona de bolla, et oltra quella çon sse çercha marche 4 de arçento, el qual elo avea trovado per fonedura, el qual tuto insembre fo fondudo per lo dito Checho e reduto in verge" $" 54$.

1388 Barcelona: "totes les dites planxes de pés de IIII onzes procehides e fetes del or de la prop dita toca, sien meses egualment ensemps, axí com se pertany, en ciment, tantes vegades tro tota la lega $\left(\mathrm{S}_{3}\right)^{55}$ sie

${ }^{50}$ Ordinatio Caroli $V$ dalphini. En Charles Dufresne, Señor Du CANGe, Glossarium mediae et infi mae latinitatis (en adelante DU CANGE), ed. París 1840-1850, tomo IV, 522, col. $3^{\mathrm{a}}$. 104.

${ }^{51}$ Carte di saggi. En De Monetis ltaliae (4 vols.), Milán 1750 (Monetis Italiae), tomo II, pág.

52 Edictum Caroli IV. En Monetis Italiae, II, pág. 266;

${ }_{53}$ Ligado es el participio de un verbo ligare, forma alternativa de alear y sus variantes.

${ }^{54}$ Venezia 1358-1556, pág. 42.

59 Como se está hablando de afinación y no de aleación, en este caso la lega no es la cantidad que se debe añadir, sino la que se debe eliminar. 
d'aquelles fora" ... "E com tota la lega $\left(S_{3}\right)$ ne sie fora, sien tornades pesar les dites planxes" 56 .

1398 Padua: "in fabricando \& cudendo libras viginti milia sextinorum nigrorum \& ad ligam $\left(\mathrm{S}_{1}\right)$ oncie unius \& quartorum duorum argenti fini... habendo remedium in dicta liga $\left(\mathrm{S}_{1}\right)$ dena rium unum argenti fini in pluri \& denarium unum argenti fini in minori" ... "si alique persone ponent argentum in zecha predicta quod non esset ad ligam $\left(S_{1}\right)$ unciarum septem et caratorum octuaginta pro marca"57.

1417 Valencia: "Com lo maestre volra ffondre argent e uolra ffer ffondicio primerament en semps ab les guardes deu aleyar son argent $a b$ coure e ab billo segons la ley $\left(S_{1}\right)$ de la moneda que deura ffer. Apres quan sera feta la liga $\left(\mathrm{S}_{2}\right)$ deu metre per cresol o per caça ço que li plaura. E com I argent passara a la liga $\left(\mathrm{S}_{2}\right)$ deuen hi esser les guardes... com lo dit argent es apunt de ley $\left(\mathrm{S}_{1}\right)$, lo dit maestre deu liurar los dits riells als obrers a pes ab lo maestre de la balança e deu saber quant li haura minuat lo dit argent en la dita ffondicio e cobrar allo" ... "Si uols aleyar moneda ab billons alts o bays serua la forma seguent: posa per exemple que uols fer moneda menuda de ley $\left(\mathrm{S}_{1}\right)$ de III diners de argent fi e has billo qui es de ley $\left(\mathrm{S}_{1}\right)$ de II diners e malla et altre billo qui es de ley $\left(\mathrm{S}_{1}\right)$ de IIII diners et altre billo qui es de ley $\left(\mathrm{S}_{1}\right)$ de III malles e altre billo qui es de ley $\left(\mathrm{S}_{1}\right)$ de III diners e malla. E uols fondre aquests billons de aquestes IIII leys $\left(S_{1}\right)$ per fer moneda menuda de ley $\left(S_{1}\right)$ de III diners $\mathrm{d}$ argent fi, seruaras la forma seguent: tu comptaras primerament dels billons de la pux baxa ley $\left(\mathrm{S}_{1}\right)$, ço es de ley $\left(\mathrm{S}_{1}\right)$ de III malles e de ley $\left(S_{1}\right)$ de II diners e malla e egualarlos has en aquesta manera, ço es que III malles e II diners e malla fan IIII diners, e axi mesclant aquests dos billons ensemps tant del I com del altre es de ley $\left(S_{1}\right)$ de IIII diners e axi comptaras la liga $\left(\mathrm{S}_{3}\right)$ del billo de III malles es coure per march $\mathrm{X}$ diners e malla, e la liga $\left(\mathrm{S}_{3}\right)$ del billo de II diners e malla es de coure VIII diners e malla per march, donchs mesclant aquests dos billons en cascun march ha de liga $\left(\mathrm{S}_{3}\right)$ de $\mathrm{X}$ diners, e II diners $\mathrm{d}$ argent, son XII diners, en lo mig march del billo de ley $\left(\mathrm{S}_{1}\right)$ de III malles d argent fi ha de coure $\mathrm{V}$ diners e pugesa, e en lo mig march del billo de ley $\left(S_{1}\right)$ de II diners e malla $d$ argent fi ha de coure IIII diners e tres pugeses doncs en lo march hauria de coure $\mathrm{X}$ diners e de argent fi II diners"

1417 Valencia: "La liga $\left(S_{3}\right)$ ques met en lo or per aleyar se met mig argent e mig coure" $"$.

1417 Valencia: "lo maestre... pesa lo dit or e tants grans com fallen del dit or del pes de I diner, tant ha de liga $\left(S_{3}\right)$ de metals en aquella sort

${ }^{36}$ ACA, reg. 1975, fols. 1 y 2. En Botet, Monedes, III, doc. XL, pág. 352.

${ }^{57}$ Monetis Italiae, I, pág. 259.

${ }^{58}$ AGRV, Tít. y enaj., vol. II, fols. 228-230. En MATEU, "Vocabulari”, doc. I, pág. 112.

${ }^{59}$ AGRV, Tít. y enaj., vol. II, fol. 231. En MATEU, "Vocabulari", doc. II, pág. 117. 
del dit or que roman e tants grans quant pesa lo dit or si tant grans ha de or fi en cascun pes de I diner del dit or" ${ }^{\prime 60}$.

1474 Milán: "quod teneantur fabricari facere marchos septem mille grossonorum valentium solidos quinque pro quolibet, qui sint numero septuaginta quinque, \& in liga $\left(\mathrm{S}_{1}\right)$ a denariis novem, hoc est, tenentis uncias sex argenti fini pro qualibet marcha, \& habeant de remedio in pondere denarium unum cum dimidio pro marcha, \& in liga $\left(\mathrm{S}_{1}\right)$ granum unum pro quarto unciae, \& sint ut supra"61.

Existe una versión en italiano de este último párrafo:

"che lo dicto magistro e compagni possano fare fabricare grossi a sol. 5 , a la liga $\left(\mathrm{S}_{1}\right)$ a den. 9 gr. - a fino che tengono onze $6 \mathrm{~d}$ 'argento a fino per marco in liga $\left(\mathrm{S}_{1}\right)$, e in numero 75 grossi per marco, \& habiano de remedio in pexo denaro uno per marca, e in liga $\left(\mathrm{S}_{1}\right)$ grano uno per quarto d'onza" ${ }^{\circ 2}$.

$$
\text { * * * }
$$

Una vez revisadas las posibilidades semánticas ofrecidas por lex y sus derivados a lo largo del período estudiado, vamos a considerar las posibilidades de que el término ventaja (realizado en nuestros textos como auantaia y auentaja) designe la cantidad de liga que hay que añadir a un metal dado para ponerlo a la ley.

De las ordenanzas medievales, sólo he encontrado este término en las dos primeras (1297 y 1334), en un mismo contexto que sólo permite afirmar que la aventaja consiste en una cierta cantidad de metal que reciben los obreros del maestro, en proporción a la cantidad trabajada, por lo que parece que sería una forma de remuneración, y entraría dentro de lo previsto por una de las acepciones que el DRAE da de ventaja ${ }^{63}$ :

1297, §4: "Et el maestro que dé el argente a los obreros linpio $\tau$ fin, $\tau$ que reçiua dellos el contrapés linpio $\tau$ fin, $\tau$ que les dé por auantaia a cada çient marcos de obra <obrada> onça $\tau$ media".

1334, §4: "E el maestro que dé a los obreros del argent linpio en fin, $\tau$ que reçiba dellos el contrapeso linpio $\tau$ en fin, $\tau$ que lo dé por auentaja a cada çient marcos de obra aleada onça $\tau$ media de obra aleada".

Estos contextos pueden ponerse en relación con los siguientes, en los que se habla de compensaciones por menguas o mermas:

6" AGRV, Tít. y enaj., vol. II, fols. 176v y ss. En MATEU, "Vocabulari”, doc. III, pág. 118.

"Monetis Italiae, II, pág. 279.

${ }_{62}$ Monetis Italiae, III, pág. 49.

${ }^{6}$ S.v. ventaja: De aventaja. 3. Sueldo sobreañadido al común que gozan otros. S.v. aventaja: Del fr. alantage. I. f. ant, ventaja. 
1369, Sevilla, §2: "que sea descontado a los dichos obreros de cada çient marcos de obra fecha quatro onzas de mengua".

1400, Cuenca, §9: "que den a los obreros por la mengua de cada çiento marcos que dieren de obra fecha de los dichos reales de a çinco dineros e dineros llanos seys onças".

En 1461, se vuelve a mezclar este concepto en el contexto de las remuneraciones:

1461, Aranda, §32: "al obrero por cada marco que labrare de quartos e medios quartos veynte dineros e por las menguas de cada marco dos dineros, e de la moneda de dineros e medios dineros que aya de cada marco que labrare quatro dineros, e por las menguas de cada marco dos dineros".

Estos dos dineros por marco, teniendo en cuenta que su talla es de 160 por marco, equivalen a 10 onzas ( 1 marco $=8$ onzas) cada 100 marcos. El hecho de que, hasta aquí, este concepto se expresase en peso y ahora en piezas, parece indicar que antes se entregaba esa cantidad de metal al obrero, o quizá se le descontaba del peso que debía entregar, mientras que ahora entrega el marco completo y recibe una compensación económica.

1462, Madrid ${ }^{64}, \S 28$ : "que el dicho my tesorero dé e pague a cada obrero por cada marco de villón que labrare tres maravedís, e asymesmo pague de las menguas que ovyere en la lavor de cada un marco otros tres maravedís ${ }^{65}$ ".

1462, Madrid, §29: "que pague el dicho my tesorero de la mengua que se fase en las syzallas e resyzallas que de la dicha moneda salen, çinco blancas de cada un marco ${ }^{66}$.

En estos dos casos la compensación equivaldría, en peso, a unas 25 onzas cada 100 marcos, siempre suponiendo que mis cuentas estén bien hechas, pues la progresión en el peso, que podría justificarse por la rebaja progresiva de la ley, me hace sospechar la existencia de algún factor que no he tenido en cuenta, ya que el trabajo de los obreros no varía dependiendo de la composición del metal, sino, en todo caso, del tamaño de las piezas.

En 1471 , Segovia ${ }^{67}, 61$, se aprueban vagamente, sin repetirlas, las remuneraciones vigentes, que deben corresponder a las de 1462. En 1497, Medina del Campo, se unifica la remuneración de los obreros en un solo concepto:

\footnotetext{
${ }^{4}$ Archivo del Ayuntamiento de Burgos, Sección Histórica, $n^{\circ}$ 1315. Ediciones: Félix-Ángel SaINZ. VARONA, "La moneda de vellón de Enrique IV.- La Ordenanza de 1462", en Boletín corporativo de la Academia Burgense 199, Burgos 1982, pp. 231-265. Edición crítica en TORRES, Ordenanzas, págs. 99-123.

${ }^{65}$ A una talla de 96 , equivale a 25 onzas cada 100 marcos.

${ }_{6}^{6}$ La talla de las blancas era de 152, por lo que cinco por marco equivalen a algo más de 25 onzas.

${ }^{67}$ AGS, DC 1, 52 (1 $1^{\text {1 }}$ hoja) y AGS, DC 4, 27 (hojas 2 a 11). Ediciones: Cortes, tomo tercero, p. 812 y ss., Madrid 1866 y Memorias de don Enrique IV de Castilla, tomo II, colección diplomática, R.A.H., Madrid 1835-1913.
} 
1497, §52: "que los obreros ayan de sus derechos por el braceaje de cada marco de oro veynte marauedís, $\tau$ de cada marco de plata doze marauedís, $\tau$ de cada marco de vellón ocho maraue dís, assí para sus derechos como para las mermas, con cargo que labren la moneda de peso cierto por los dinerales que les diere el maestro de balança $\tau$ que assí lo rindan como lo rescibieron sin descontar mermas".

Ventaja vuelve a aparecer en castellano en un texto de 1442 que veremos luego, después de revisar las ocurrencias encontradas en otros ámbitos lingüísticos, fundamentalmente el catalán.

El texto de 1296 , Alicante, $\$ 4$, se ajusta aun más, si cabe, a la interpretación que acabo de proponer, ya que se inscribe en el contexto de las remuneraciones: "E quel maestre do als obrers, per obratge de cascun march que be obraran, VIII diners e mala e I mala de ventayla de la moneda menuda. E per obratge de la moneda d'argent desus dita, VIII diners per cascun march".

Du Cange lo define también como una remuneración: "Premium, quod ultra pretium conventum operario datur"68; lo que hoy llamaríamos prima. Cita como autoridad este mismo párrafo catalán de 1296 , y remite a avantagium 3, donde dice: "Quidquid emolumenti concedi tur operariis praeter constitutam mercedem", traduce al francés como avantage, utilité, profit, $\mathrm{y}$, entre las autoridades, cita un edicto del emperador Enrique IV, de 1311, por lo que debe referirse a Enrique VII ${ }^{69}$. Sin relación con la moneda, da esta otra cita: "Sint contenti labora tores, nec nil petant ultra 5 solidos taxatos per curiam, nec nil petant pro lingonibus, nec pro vino companagio, nec de alio avantagio" 70 .

Pero ya en 1362, en un texto datado en Perpignan, el término avantatge se aplica a otro concepto: "lo senyor rey, de la ley del florí que per ordinació era e es acostumat de batre en Perpenyà a ley de XXII quirats e III quarts, han levats e remogut en lo present arrendament los III quarts, romanent la ley en XXII quirats segons que en lo primer capítol n'es feta menció; e axó fa lo senyor rey per tal quels dits arrendadors pusquen donar aquest avantatge dels III quarts, qui poden valer tro a XXV sols. barchinonesos per cascun march, als mercaders que y aportaran or, e la secha haia que obrar e major aviament, de ques segueix profit a cascuna part"71. El único rasgo común entre uno y otro uso me parece que es la idea de 'lo que está por encima de una cantidad o magnitud fijada'. Pero en este texto catalán, si afinamos el análisis, podemos ya relacionar, aunque a manera de hipótesis, el avantatge con la cantidad de metal que hay que añadirle, en este caso quitarle, al oro para rebajar su ley.

${ }^{68}$ DU CANGE, I, pág. 97, 2. adventagium.

${ }^{64}$ Éste es el extracto del edicto de Enrique VII, según Monetis ltaliae, II, pág. 263; Edictum Henrici VII: "non debent dicti operarii \& monetarii petere a nobis sive a magistris monetarum nostrarum aliud donum sive advantagium aliqua causa, praeterquam suum justum salarium superius ordinatum".

${ }^{70}$ Consilia Communiae Massil. MSS.

${ }^{71}$ ACA, reg. 1293, fol. 98. En Botet, Monedes, III, doc. XXXIV, pág. 330. 
El siguiente texto, también catalán, vuelve a relacionar el término con la obtención de la ley del metal, y, lo que es más importante, aporta una oposición tara / avantatge, apoyada por prendre / dar (sic), que, si no me equivoco, equivale a 'reducción' / 'aumento' o a 'lo que se quita' / 'lo que se agrega'.

1388 Barcelona: "los dits Maestres e los scrivans reyals sien tenguts e degen dar clara e verdadera informació a les dites guardes de les leys e or fi a que seran e tendran los ors que alleyaran, e axí matex certificarlos quines tares hauran preses e quins e quals avantatges hauran dats, e açò a fi quels alleyaments ques faran, axí dels florins de ley de XVIII quirats d'or fi el march com dels florins a ley de florí de Florença, sien fets justament"72.

Tara podría ser la parte del peso de metal fino que debe detraerse para obtener la equivalencia (el resto) en metal rebajado de ley, en tanto que el avantatge sería la cantidad (en peso) de liga que ha de añadirse. Si esto es así, ambas cantidades serían idénticas, variando la sustancia medida. La dificultad de esta interpretación, que puede mantenerse, no obstante, por tratarse de un texto teórico, reside en que, en la práctica, las aleaciones se realizaban mediante la aplicación de unas tablas de equivalencia previamente elaboradas, que indicaban de modo automático la cantidad de liga que era necesario añadir a una masa de metal de determinado peso y composición. Por cierto, que tara es uno de los arabismos técnicos en catalán que no encontramos en los textos castellanos de la misma época ${ }^{73}$.

Este sentido de 'parte de metal secundario añadido en la aleación' lo encontramos también en este texto valenciano de 1417: "lo ensayador en presencia de les guardes deu pendre de la moneda que les guardes haurán pres de cascun fornal fins en I onza e deu la trencar per mig ab tesora e de la vna meytat deu pendre lo enssay son just pes, e aquella meta en çendrada e quant lo haura aportat a son punt, axi com deu esser ensay de espanya, deu portar lo dit ensay dauant les dites guardes, les quals deuen guardar que no sia massa sostengut ne massa pesat e deuen comptar ço quel ensayador troba de auantatge de la moneda al asay e si nol tenen per bell quen facen fer altre" ${ }^{74}$. Como el ensaye "por fuego" consistía en purificar el oro o la plata eliminando el resto de la composición, la diferencia de peso entre la muestra inicial y la final era el peso de la liga (aquí avantatge), y mediante un cálculo o la consulta de unas tablas, se averiguaba la ley de la muestra inicial.

Aparte de las que considero grandes ordenanzas medievales, en un texto castellano de 1442, hallamos una ocurrencia de aventaja que podría ajustarse

${ }^{72}$ ACA, reg. 1975, fols. 1 y 2. En Botet, Monedes, III, doc. XL, pág. 352.

${ }_{73}^{73}$ DCECH, V, pág. 412 , col. 1. Documenta en castellano atara a principios del siglo XV (Cancionero de Baena), y tara en 1505 (Pedro de Alcalá). Para la aparente mayor arabización del vocabulario técnico catalán, ver las conclusiones de TORRES, Ordenanzas, especialmente págs. 727-728 y 734735.

${ }^{74}$ AGRV, Tít. y enaj., vol. II, fols. 228-230. En MATEU, "Vocabulari", doc. I, pág. 112. 
al sentido que estamos viendo en la documentación catalana: "que la dicha moneda que agora yo mando facer sea bien monedeada e redondeada e tallada, por quanto las otras blancas que yo agora mando desfacer son mal monedadas e non redondas, nin bien fechas, e paresca en ésta el aventaja de buena moneda"75. La oposición ley / aventaja que estamos suponiendo, implica que en el discurso se puede elegir entre el uso de uno u otro términos, cada uno dentro de su contexto discursivo propio, para expresar lo mismo, puesto que el microsistema significativo 'composición del metal' lo conforman totalmente esos dos componentes, de manera que la utilización de uno implica al otro:

$$
\begin{gathered}
\mathrm{a}=\mathrm{b}+\mathrm{c} \\
\text { si } \mathrm{b}=n, \mathrm{c}=\mathrm{a}-n
\end{gathered}
$$

Creo que queda demostrado para el catalán este sentido especializado y no meramente eventual, hoy perdido, del término (a)ventaja que probablemente entraría en desuso al perderse, a lo que parece ya fuera de la Edad Media, la identificación ley = liga que hemos visto, y especializarse liga como 'parte de metal secundario añadida en la aleación'. Pero la concentración del fenómeno en esta lengua y su aislada aparición en castellano no autorizan a postular que el término se usara realmente en la terminología de este último. Lo que sí apoya esa ocurrencia única es la tendencia de la terminología castellana de esta época a beber en fuentes del reino vecino ${ }^{76}$.

Una vez analizado ventaja, podemos ocuparnos de otro término, mejoría:

1297, Lorca / 1334, Murcia ${ }^{77}$ : "si más de vn grano menguare que tomen las guardas todos los dineros $\tau$ que los fagan refondir ante sí, $\tau$ el maestro que meta y la meioría ante ellos $\tau$ ante el escriuano".

Incurriendo quizá en un leve anacronismo, podemos establecer una oposición ventaja / mejoría, que respondería a los rasgos $<$ de metal secundario $>/<$ de metal principal $>$, designando ambos términos una cantidad que se añade, en tanto que tara era una cantidad que se restaba. Mejoría es, en caso de ser un término técnico y no una utilización casual del sustantivo corriente, una parte de metal primario que se añade a una mezcla para aumentar su ley.

Aunque el sistema de medición de la ley no es excesivamente complejo, haré aquí un inciso para exponerlo más claramente, partiendo de la información facilitada por el conocido platero Juan de Arfe. Si bien no lo explica directamente, se puede ver que la ley de la plata pura es de 12 dineros, y que cada

${ }^{75} \mathrm{Juan}$ II; Ordenamiento para labrar moneda en las casas della. En HeISS, Descripción, I, 301, XVIII y SÁEZ, Juan II, pág. 97, VII.

${ }_{76}$ Una de las conclusiones generales de TORRES, Ordenanzas era que la terminología técnica debía originarse en territorios europeos (Francia, Alemania, Norte de Italia) y desplazarse hacia el sur, junto con la tecnología y la documentación, llegando a Castilla a través de los territorios pirenaicos.

${ }^{77}$ Párrafo 13 de ambos. 
uno de estos dineros se divide en 24 granos $^{78}$. El oro puro es de 24 quilates $^{79}$, pero no habla tampoco Arfe del submúltiplo del quilate, el grano, que es un cuarto de quilate.

Para resumir todo lo dicho, en el esquema que sigue se puede ver la distribución cronológica y espacial de los términos y sus sentidos. He incluido también las ocurrencias de verbos de la familia de mezclar y miscere cuando su sentido está relacionado conceptualmente con alear. Las abreviaturas de los diversos ámbitos lingüísticos son:

- cast (castellano)

- cat (catalán)

- fr (francés)

- it (italiano)

- port (portugués)

- cualquiera de ellas precedida de lat indica que el texto está escrito en latín en territorios hoy pertenecientes a ese ámbito. Las dos primeras ocurrencias se pueden considerar como pertenecientes a la tradición latina culta.

\begin{tabular}{|c|c|c|c|}
\hline Fecha & Término & Ámbito & Sentido \\
\hline S. VII & permixtione & $1 t^{80}$ & \\
\hline 864 & mixtum/mixturam & $l a t^{81}$ & \\
\hline 1119 & ley & cat & $S_{1}$ \\
\hline $1162-1196$ & legalem & lat/cat & 'de ley' \\
\hline $1162-1196$ & lege & lat/cat & $S_{1}$ \\
\hline 1174 & lege & lat/cat & $\mathbf{S}_{1}$ \\
\hline 1180 & loy & fr & $S_{1}^{\prime}$ \\
\hline 1202 & lege & lat/fr & $S_{1}^{\prime}$ \\
\hline 1211 & mesturar/misturar & port & \\
\hline 1222 & lege & lat/cat & $\mathbf{S}_{1}$ \\
\hline 1224 & lege & lat/cat & $S_{1}$ \\
\hline 1226 & lege & $\mathrm{lat} / \mathrm{fr}$ & $S_{1}$ \\
\hline 1247 & legem/legis & lat/cat & $\mathrm{S}_{1}$ \\
\hline 1249 & lege/legem/legis & lat/cat & $S_{1}$ \\
\hline
\end{tabular}

${ }^{78}$ Juan DE ARFE y VILLAFAÑE, Quilatador de la plata, oro y piedras (ARFE, Quilatador), Valladolid 1572, fol.11.

${ }^{79}$ ARFE, Quilatador, fol. 23v.

${ }^{80}$ Liber Iudiciorum sive Lex Visigothorum, en Monumenta Germaniae Historica, Legum (MGH, Legum) Sectio I. Legum Nationum Germanicarum. Tomus I. Leges Visigothorum, Hannover-Leipzig 1902, VII, 6, 3.

${ }^{81}$ Edictum pistense. En $M G H$, Legum I, pág. 488 y ss. 


\begin{tabular}{|c|c|c|c|}
\hline Fecha & Término & Ámbito & Sentido \\
\hline 1249 & $\begin{array}{l}\text { alliamento/ } \\
\text { alleamenti }\end{array}$ & lat & \\
\hline 1251 & legis/legem & lat/fr & $S_{1}$ \\
\hline 1256 & lege & lat/cat & $S_{1}$ \\
\hline 1256 & mescle & $\mathrm{cat}^{82}$ & \\
\hline 1257 & aleyada & lat/cat & \\
\hline 1257 & legalis & & 'de ley' \\
\hline 1257 & legis/lege & & $S_{1}$ \\
\hline 1261 & legem & lat/port & $S_{1} / S_{2}$ \\
\hline 1262 & lege & lat/cat & $\mathrm{S}_{1}$ \\
\hline 1263 & legem & lat/cat & $S_{1}^{\prime}$ \\
\hline 1265 & lege & lat/cat & $S_{1}$ \\
\hline 1266 & aloy & fr & $S_{1}^{\prime}$ \\
\hline 1266 & loy & fr & $S_{1}$ \\
\hline 1267 & lege & lat/fr & $\mathrm{S}_{1}$ \\
\hline 1268 & ly & cast & $\mathrm{S}_{1}$ \\
\hline 1272 & lex & lat/fr & $S_{1}^{2}$ \\
\hline 1272 & lege/legem/legis & lat/cat & $S_{1}$ \\
\hline 1274 & legali & lat/cat & 'de ley' \\
\hline 1274 & legales (personas) & lat/cat & 'leales' 83 \\
\hline 1274 & legem & lat/cat & $S_{1}$ \\
\hline 1275 & allegiés, alegent & fr? & \\
\hline 1278 & legis/legem & lat/fr & $\mathrm{S}_{1}$ \\
\hline 1296 & ley & cat & $S_{1}$ \\
\hline 1297 & ley & cast & $S_{1}^{\prime}$ \\
\hline 1303 & loy & $\mathrm{fr}$ & $S_{1}$ \\
\hline 1306 & loy & fr & $S_{1}$ \\
\hline 1308 & aleyar/aleyat & cat & \\
\hline 1308 & lia & cat & $S_{2 b}$ \\
\hline 1310 & loy & fr & $\mathrm{S}_{1}^{20}$ \\
\hline 1314 & loy & fr & $S_{1}$ \\
\hline 1322 & aloy & $\mathrm{fr}$ & $S_{1}^{\prime}$ \\
\hline 1331 & alleyat $^{84}$ & cat & \\
\hline 1331 & ley & cat & $S_{1}$ \\
\hline 1334 & ley & cast & $S_{1}$ \\
\hline 1334 & aleada & cast & \\
\hline 1338 & alleyat & cat & \\
\hline 1338 & lege/legem/legis & lat/cat & \\
\hline
\end{tabular}

${ }^{82}$ El documento está redactado en latín, pero el término es, evidentemente, romance.

${ }^{83}$ Consigno únicamente la primera aparición de este sentido. No he consignado ocurrencias anteriores de legaliter, referido a la fabricación de la moneda, que puede interpretarse como 'lealmente' o 'de acuerdo a la ley', en un sentido más general.

${ }^{84}$ Este participio aparece repetidamente en este documento y en el de 1338 que lo reproduce. 


\begin{tabular}{|c|c|c|c|}
\hline Fecha & Término & Ámbito & Sentido \\
\hline 1338 & lege & & $\mathrm{S}_{3}$ \\
\hline 1338 & ley & cat & $\mathrm{S}_{1}^{3}$ \\
\hline 1342 & loy & fr & $S_{1}$ \\
\hline 1346 & loy & fr & $\mathbf{S}_{1}$ \\
\hline 1346 & aloyer & fr & \\
\hline 1347 & loy & $\mathrm{fr}$ & $\mathrm{S}_{1}$ \\
\hline 1347 & loy & fr & $\mathrm{S}_{2} ?$ \\
\hline 1347 & alloy & $\mathrm{fr}$ & $\mathrm{S}_{2} / \mathrm{S}_{3} ?$ \\
\hline 1347 & alloie (verbo) & $\mathrm{fr}$ & \\
\hline 1348 & loy & fr & \\
\hline 1348 & alloier & fr & \\
\hline 1349 & legis & lat/cat & $S_{1}$ \\
\hline 1349 & loy & $\mathrm{fr}$ & $\mathbf{S}_{1}$ \\
\hline 1349 & loy & $\mathrm{fr}$ & $\tilde{S}_{2 b}$ \\
\hline $1351^{85}$ & loy & $\mathrm{fr}$ & $S_{2 b}^{20}$ \\
\hline 1356 & liga & cat & $\mathrm{S}_{1}$ \\
\hline 1356 & liga & cat & $\mathrm{S}_{3}$ \\
\hline 1357 & liga & lat/fr & $S_{1}^{3}$ \\
\hline 1360 & liga & $\mathrm{lat} / \mathrm{it}$ & $\mathbf{S}_{1}$ \\
\hline 1363 & ligis/ligae & lat/fr & $S_{1}$ \\
\hline 1368 & alleyant/alleyats & cat & \\
\hline 1368 & leys/ley & cat & $\mathbf{S}_{1}$ \\
\hline 1369 & ley & cast & $S_{1}, S_{3}$ \\
\hline 1369 & liga & cast & $\mathrm{S}_{1}$ \\
\hline 1381 & ligado & it & 'mezclado' \\
\hline 1381 & liga & it & $\mathrm{S}_{2}$ \\
\hline 1388 & lega & cat & $\mathrm{S}_{3}\left(\right.$ ley para $\left.\mathrm{s}_{1}\right)$ \\
\hline 1388 & alleyats/alleyaran & cat & \\
\hline 1398 & liga & lat/it & $S_{1}$ \\
\hline 1417 & aleyar & cat & \\
\hline 1417 & liga & cat & $S_{2}$ y $S_{3}\left(\right.$ ley para $\left.S_{1}\right)$ \\
\hline 1417 & mesclant/mescla & cat & \\
\hline 1442 & aleadas & cast & \\
\hline 1460 & alear/alliar & port & \\
\hline 1474 & liga & lat $\mathrm{e}$ it & $S_{1}$ \\
\hline 1478 & ligadura & cast & $\mathrm{S}_{3}$ \\
\hline 1497 & aleación & cast & $\mathrm{S}_{2}^{3}$ \\
\hline
\end{tabular}

${ }^{85}$ Para no alargar innecesariamente esta tabla concluyo aquí el registro de ocurrencias de ley, loy, etc., salvo casos que aporten algún dato de interés. 